JAE-YEON KIM*, JUNG-WOO HWANG*, HYE-YOUNG KIM*, SEUNG-MI LEE*, WOO-SANG JUNG**, JAI-WON BYEON*\#

\title{
FABRICATION OF AZ31/CNT SURFACE NANO-COMPOSITE BY DOUBLE-PASS FRICTION STIR PROCESSING
}

\begin{abstract}
Double-pass Friction Stir Processing (FSP) was applied to fabricate an AZ31/CNT nano-composite for surface hardening of lightweight structural components. The effects of double-pass FSP as well as groove depth (i.e., volume fraction of CNT) on the CNT distribution, dynamically recrystallized grain size, and resulting microhardness were studied. Double-pass FSP was performed for the CNT-filled plate-type specimen with different groove depths of 2, 3, and $4 \mathrm{~mm}$. By applying double-pass FSP, the average size of CNT clusters decreased, implying a more homogeneous distribution. Compared with the FSPed specimen without CNT, grain size was refined from $19 \mu \mathrm{m}$ to $3 \mu \mathrm{m}$ and microhardness increased from $52 \mathrm{Hv}$ to $83 \mathrm{Hv}$ (i.e., $71 \%$ increase).
\end{abstract}

Keywords: Surface Modification, Double-pass Friction Stir Processing, AZ31, Composite, CNT

\section{Introduction}

Magnesium alloys have been considered for lightweight transportation structures and case of electronic device. Composite fabrication processes, such as powder sintering and squeeze casting, have been developed for improving the weak mechanical strength of the alloys [1]. Recently, following the development of solid-state friction stir welding, friction stir processing (FSP) has received attention as a new technique for the fabrication of metal matrix surface composites (MMSC) [2]. Composite can be fabricated during severe plastic deformation of the matrix accompanying dispersion of reinforcement particles by mechanical stirring of a high-speed rotational tool. To date, the fabrications of aluminum or copper $/ \mathrm{Al}_{2} \mathrm{O}_{3}, \mathrm{~B}_{4} \mathrm{C}, \mathrm{SiC}$, or $\mathrm{CNT}$ composites of easily deformable Face-Centered-Cubic (FCC) structures have been reported [2-6]. However, fabrications studies of magnesium matrix composite with Hexagonal-Close-Packing (HCP) atomic structure were less. Effects of process variables including rotational speed, travelling speed, number of pass and tool design on the homogeneous distribution of reinforcement particles have been reported for magnesium matrix composite $[7,8]$. This study attempted to fabricate less deformable HCP AZ31 magnesium alloy/CNT composite by double-pass FSP. In particular, the effects of double-pass FSP and the volume fraction of reinforcement particles on the dispersion of CNT and microhardness were investigated.

\section{Experimental}

A rolled AZ31B-O Mg alloy plate (Magnesium Gurnee Metal Co. Ltd., China) was used for this study. The size of the specimen for FSP was $120 \mathrm{~mm}$ in length, $60 \mathrm{~mm}$ in width, and $6 \mathrm{~mm}$ in thickness. The chemical composition of the alloy was $\mathrm{Mg}$ : balance, $\mathrm{Al}$ : 2.5-3.5, $\mathrm{Zn}: 0.6-1.4, \mathrm{Mn}: 0.2-1.0, \mathrm{Si}:<0.1$, Fe: $<0.005, \mathrm{Cu}:<0.04$, and $\mathrm{Ni}:<0.005$ mass $\%$. The CNT with a purity of $97 \%$ (CNT Co. Ltd., Korea) used in this study was $10-30 \mathrm{~nm}$ in diameter and $1-25 \mu \mathrm{m}$ in length. The rotation tool made of SKD61 steel had a shoulder diameter of $16 \mathrm{~mm}$, pin diameter of $4 \mathrm{~mm}$, and pin length of $4 \mathrm{~mm}$. The pin was designed with a screw-shape for improving the stirring effectiveness. The stirring tool was tilted at a $3^{\circ}$ forward angle from the vertical. In order to construct a processing parameter map showing the soundness of the stir zone depending on the rotational and travel speed of the tool, single-pass FSP was performed for the AZ31 specimen without CNT at various processing conditions of a rotation speed ranging 715-1400 rpm (i.e., 715, 1000, and $1400 \mathrm{rpm})$ and a travel speed ranging $25-210 \mathrm{~mm} / \mathrm{min}(25,95$, 157 , and $210 \mathrm{~mm} / \mathrm{min}$ ). To fabricate the surface composites with different CNT fraction, the strengthening material was compactly inserted into the grooves of $1 \mathrm{~mm}$ in width and $2 \mathrm{~mm}, 3 \mathrm{~mm}$, or $4 \mathrm{~mm}$ in depth, respectively. Single-pass and double-pass FSP were conducted by using the best condition determined from the processing parameter map (i.e., $1400 \mathrm{rpm}$ and $25 \mathrm{~mm} / \mathrm{min}$ ). The microstructure was observed by an Optical Microscope (OM) and Scanning Electron Microscope (SEM). The Vickers hardness was measured on a cross-section of the stir zone.

\footnotetext{
* DEPARTMENT OF MATERIALS SCIENCE \& ENGINEERING, SEOUL NATIONAL UNIVERSITY OF SCIENCE AND TECHNOLOGY, SEOUL, KOREA

** HIGH TEMPERATURE ENERGY MATERIALS RESEARCH CENTER, KOREA INSTITUTE OF SCIENCE AND TECHNOLOGY, SEOUL, KOREA

\# Corresponding author: byeonjw@seoultech.ac.kr
} 


\section{Results and discussion}

A cross-section of the stir zone was macroscopically observed to check the successful formation of stir zone without macro defects, as typically shown in Fig. 1(a) and (b). In order to construct processing parameter map based on the soundness of the stir zone, the pseudo-heat index (W, Eq. (1)) [2] developed for reflecting the effective heat input during the FSP of Al alloys was adopted.

$$
W=w^{2} / v
$$

where $w$ and $v$ are the rotational speed (rpm) and the travel speed ( $\mathrm{mm} / \mathrm{min})$, respectively. Fig. 1 (c) shows a processing parameter map constructed for the FSPed AZ31 magnesium alloy. In this map, the soundness of each FSPed specimen is qualitatively represented in three levels (i.e., no macro defect (circle), small defect (triangle), large defect (x-mark)) based on the cross-sectional observations, as shown in Fig. 1 (a) and (b). A sounder stir zone was formed under a higher heat input condition. As a quantitative reference, the lines with constant heat index $(W)$ value were plotted. When the heat index value was over $2.0 \times 10^{4}$, a sound stir zone without macro defects was successfully formed. With decreasing heat index value, a large tunneling defect was formed at the bottom of the advancing side (AS) due to an insufficient heat input [6], as shown in Fig. 1 (b).

Fig. 1 (d) and (e) shows optical microstructure of the asreceived and stir zone (i.e., Fig. 1 (a) specimen), respectively. A refined grain size of about $19 \mu \mathrm{m}$ in the stir zone was obtained due to dynamic recrystallization by plastic deformation and frictional heat between the rotating tool and AZ31 alloy with an average grain size of $35 \mu \mathrm{m}$. To investigate the effect of CNT volume fraction and number of passes on the CNT dispersion, double-pass FSP was performed for the specimens with a groove depth of 2, 3, and $4 \mathrm{~mm}$, respectively. The processing condition of $1400 \mathrm{rpm}$ and $25 \mathrm{~mm} / \mathrm{min}$ with the biggest heat index value in Fig. 1 (c) was applied for the friction stirring.

Fig. 2 shows cross-sectional SEM images of the stir zone in the AZ31/CNT composite specimens. Regardless of the groove depth (i.e., volume fraction of CNT) as well as the number of FSP passes, clusters in which individual CNTs were agglomerated were observed in the stir zone. Fig. 3 shows the distribution of cluster size as a function of groove depth and number of passes. The average cluster size in the single-passed specimens with groove depths of $2 \mathrm{~mm}, 3 \mathrm{~mm}$, and $4 \mathrm{~mm}$ was measured as 455 , 788 , and $784 \mathrm{~nm}$, respectively. The cluster size was reduced to 325,624 , and $702 \mathrm{~nm}$, respectively, as a result of double-pass FSP. This decreasing tendency was more prominent at shallower groove depths.

Grain refinement down to about $3 \mu \mathrm{m}$ was observed for the specimen with a groove depth of $2 \mathrm{~mm}$ by single-pass FSP. Grain refinement of the FSPed AZ31/CNT composite was remarkable compared with that of the FSPed specimen without CNT dispersion (i.e., $19 \mu \mathrm{m}$ as shown in Fig. 1(e)), implying CNT dispersion by FSP was effective for grain refinement via the grain boundary. The reduced cluster size by double-pass
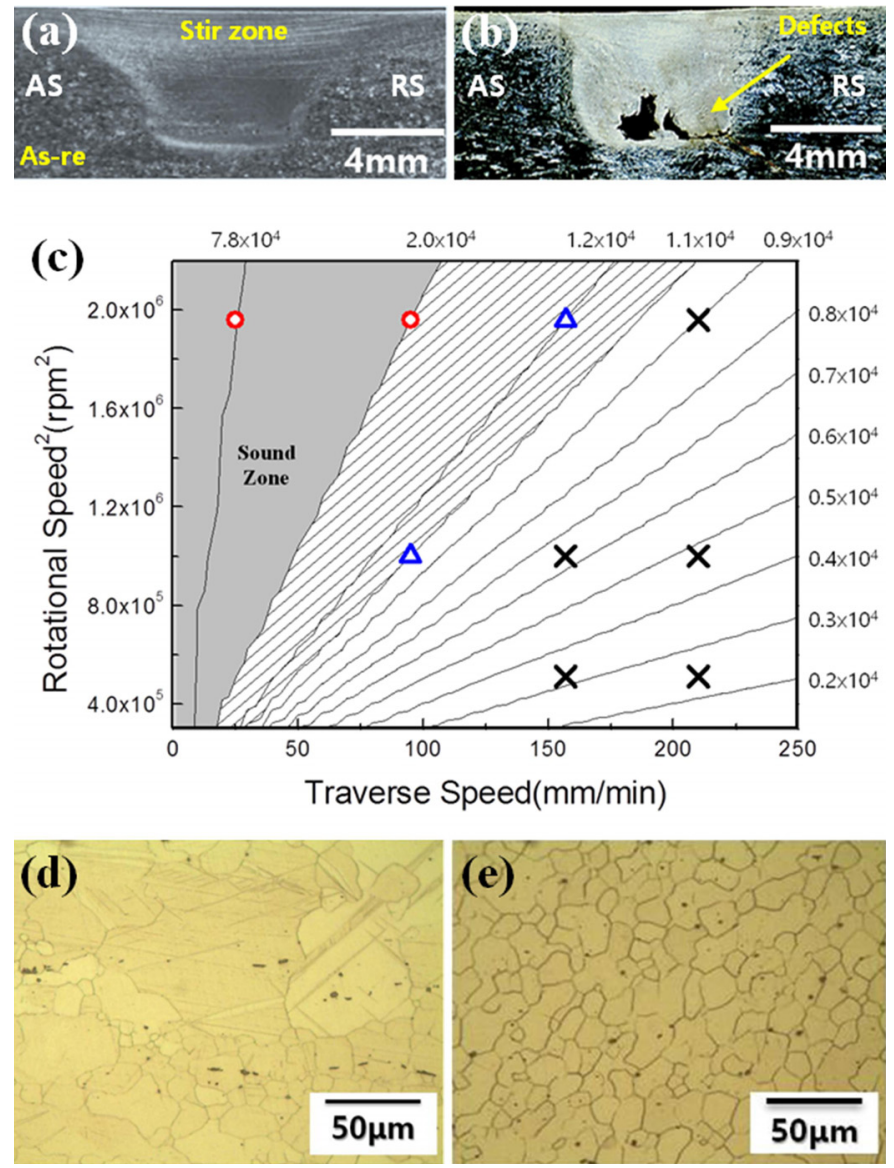

Fig. 1. A typical cross-sectional macro image of the stir zone (a) without defect (1400 rpm, $25 \mathrm{~mm} / \mathrm{min}$ ) and (b) with macro defect $(715 \mathrm{rpm}$, $210 \mathrm{~mm} / \mathrm{min})$. Here, AS and RS denotes advancing side and retreating side of the stir zone, respectively. (c) processing parameter map based on macro-soundness of the stir zone. An optical microstructure of (d) the as-received and (e) stir zone of the (a) specimen

FSP may more effectively inhibit grain growth and increase microhardness by grain boundary strengthening.

Fig. 4 shows the hardness variation of the double-FSPed specimen with a relatively uniform distribution of CNT, as a function of groove depth. No increase in hardness was observed for the FSPed specimen without CNT comparing with the as-received rolled AZ31 alloy. This is believed to be due to development of dynamically recrystallized grain of low dislocation density in the FSPed specimen. On the other hand, the hardness in the stir zone of the composites increased with increasing groove depth. The CNT distributed by friction stir process has been reported to have strong interfacial bonding with magnesium matrix and hence effectively increase mechanical strength of the composite [4]. In this respect, the hardness increase in this study can be attributed to the grain refinement due to grain boundary pinning of CNT (i.e., Fig. 2) as well as dispersion strengthening mechanism by individual CNT in the grain [4].

The average microhardness $(83 \mathrm{Hv})$ of the double-passed AZ31/CNT composite of $4 \mathrm{~mm}$ groove depth increased about $71 \%$ compared with that $(52 \mathrm{Hv})$ of the FSPed AZ31 without CNT. Increasing groove depth was beneficial for hardness improvement by increasing the volume fraction of CNT. 

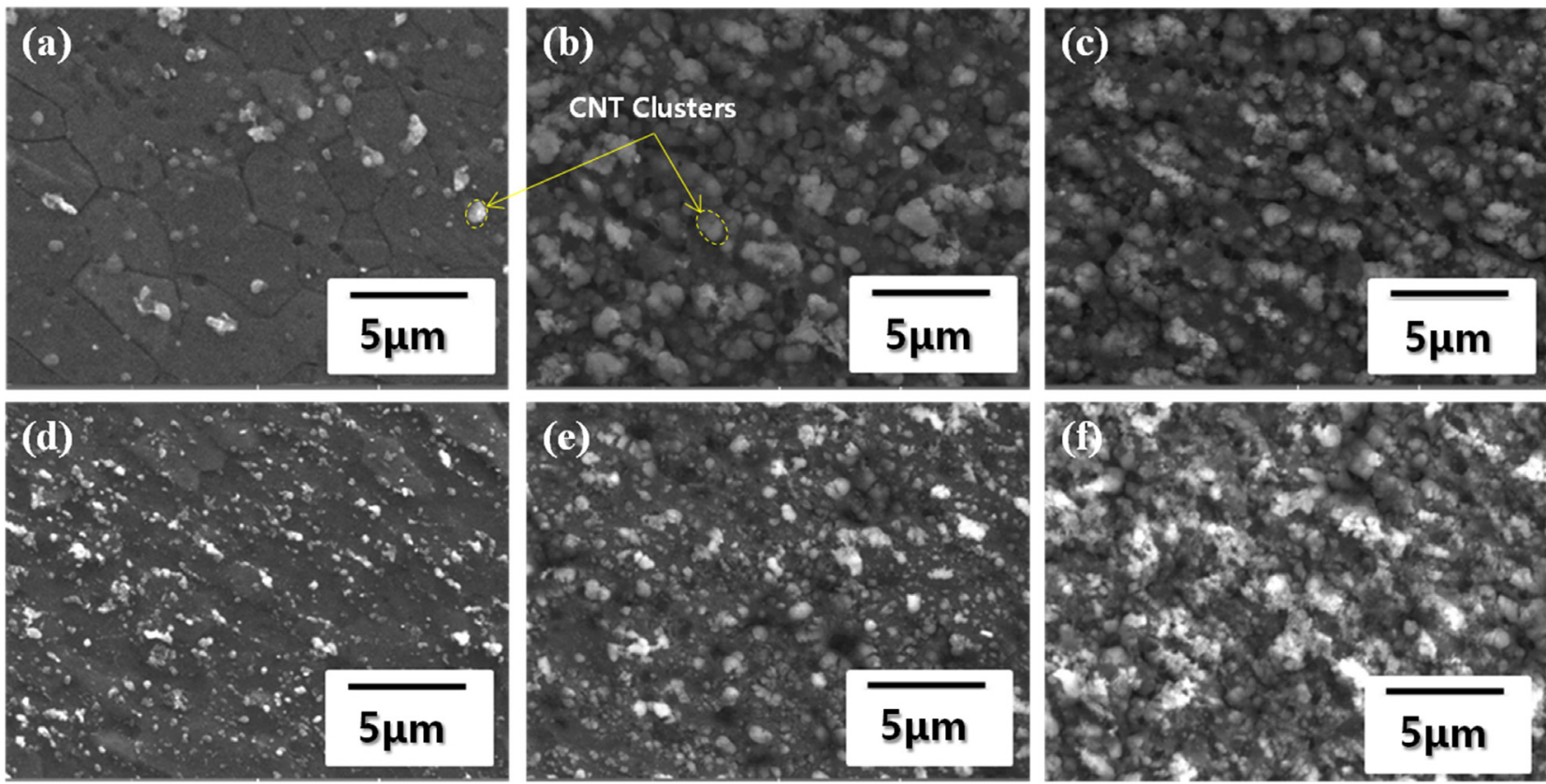

Fig. 2. Cross sectional SEM images of the stir zone in AZ31/CNT composite with number of FSP passes and groove depth: (a) 1 pass/2 mm, (b) 1 pass $/ 3 \mathrm{~mm}$, (c) 1 pass $/ 4 \mathrm{~mm}$, (d) 2 pass $/ 2 \mathrm{~mm}$, (e) 2 pass $/ 3 \mathrm{~mm}$, and (f) 2 pass $/ 4 \mathrm{~mm}$
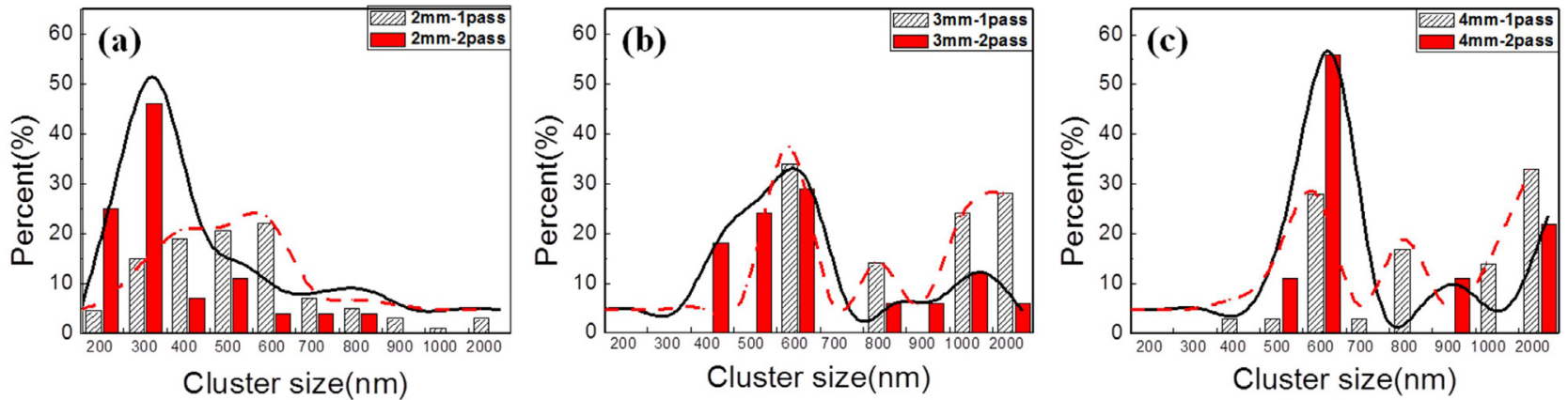

Fig. 3. Comparison of size of CNT clusters between single- and double-FSPed specimen with different groove depths of (a) $2 \mathrm{~mm}$, (b) $3 \mathrm{~mm}$, and (c) $4 \mathrm{~mm}$, respectively

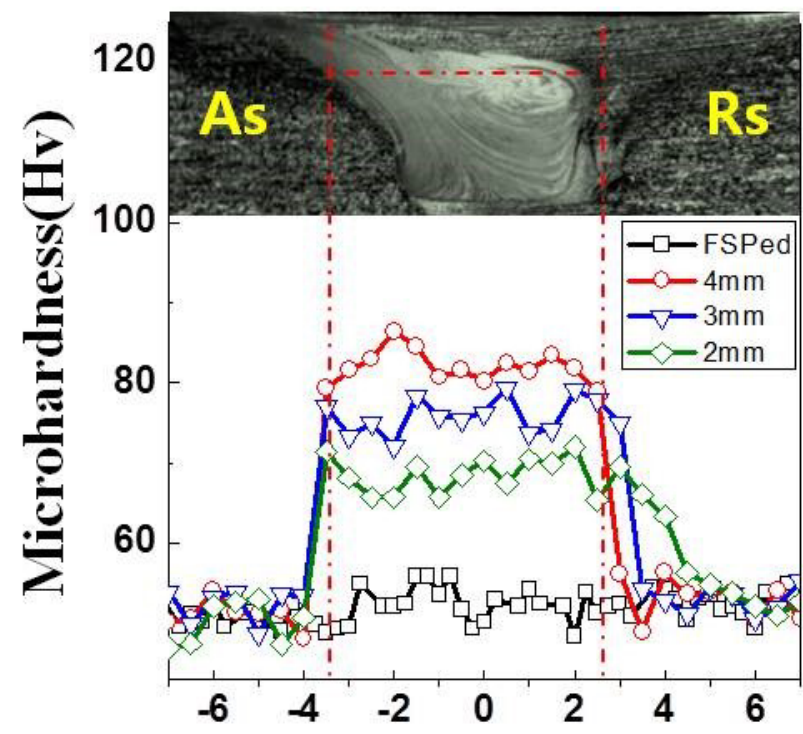

Distance from stir zone $(\mathbf{m m})$

Fig. 4. Variation of microhardness in stir zone of the double-FSPed specimen as a function of groove depth

\section{Conclusions}

AZ31/CNT surface composites with different volume of CNT were successfully fabricated by applying double-pass FSP. In order to optimize the processing condition, a processing parameter map was developed based on a heat index value defined by square of rotational speed over tool travel speed. Double-pass FSP was more effective for a more homogeneous distribution of the strengthening second phase than single-pass process. Compared with the FSPed specimen without CNT, the double-FSPed specimen with a groove depth of $4 \mathrm{~mm}$ (i.e., the largest volume of CNT in this work) showed a $71 \%$ increase in microhardness, suggesting the feasibility of double-pass FSP for fabricating high strength magnesium-matrix composites.

\section{Acknowledgments}

This work was supported by Korea Institute of Science and Technology (KIST: 2E 25322-15-081). 
1042

\section{REFERENCES}

[1] Q.B. Nguyen, M. Gupta, J. Alloy. Comp. 459, 244-250 (2008).

[2] R.S. Mishra, Z.Y. Ma, Mater. Sci. Eng. R. 50, 1-78 (2005).

[3] R. Sathiskumar, N. Murugan, I. Dinaharan, S.J. Vijay, Mater. Design 55, 224-234 (2014).

[4] Q. Liu, L. Ke, F. Liu, C. Huang, L. Xing, Mater. Design 45, 343348 (2013).
[5] S. Sahraeinejad, H. Izadi, M. Haghshenas, A.P. Gerlich, Mater. Sci. Eng. A. 626, 505-513 (2015).

[6] P.L. Threadgill, A.J. Leonard, H.R. Shercliff, P.J. Withers, Int. Mater. Rev. 54, 49-93 (2009).

[7] M. Azizieh, A.H. Kokabi, P. Abachi, Mater. Design 32, 2034-2041 (2011).

[8] M. Abbasi, B. Bagheri, M. Dadaei, H.R. Omodvar, M. Rezaei, Int. J. Adv. Manuf. Technol. 77, 2051-2058 (2015). 